
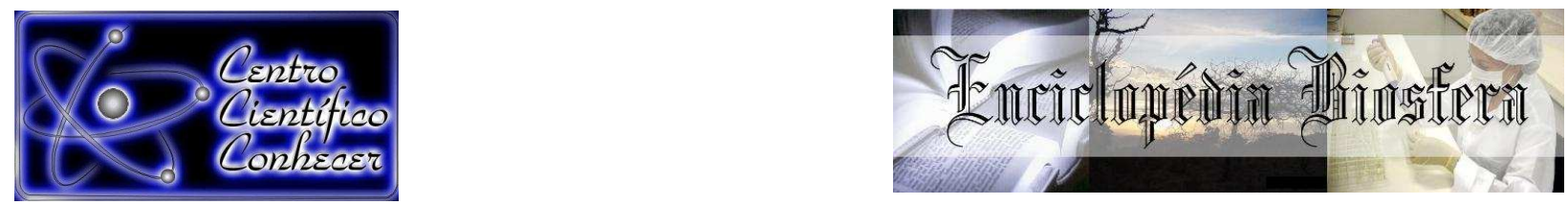

\title{
CONHECIMENTO DE MULHERES USUÁRIAS DO SUS SOBRE O HPV NA REGIÃO NORTE DO ESPÍRITO SANTO
}

\author{
Raphaela de Aguiar Freitas ${ }^{1}$, Lorena Vilela Cangussú ${ }^{2}$, Débora Barreto Teresa \\ Gradella $^{3}$
}

1 Graduanda de Farmácia pela Universidade Federal do Espírito Santo, São Mateus, ES - Brasil

2 Farmacêutica pela Universidade Federal do Espírito Santo, São Mateus, ES Brasil

3 Profa Doutora do Departamento de Ciências da Saúde da Universidade Federal do Espírito Santo (debora.gradella@ufes.br), São Mateus, ES - Brasil

Recebido em: 08/09/2015 - Aprovado em: 14/11/2015 - Publicado em: 01/12/2015 DOI: http://dx.doi.org/10.18677/Enciclopedia_Biosfera_2015_040

\begin{abstract}
O HPV é um vírus que apresenta tropismo por células epiteliais causando infecções na pele e mucosas e entre $75 \%$ a $80 \%$ da população mundial adquirem um ou mais tipos de HPV em algum momento da vida. A forma de transmissão é principalmente sexual, sendo que o vírus pode originar lesões precursoras do câncer do colo do útero. Entre as formas de prevenção estão a utilização de preservativos e a vacinação. Assim, o presente estudo avaliou o conhecimento das mulheres usuárias do SUS a respeito do HPV. Foi realizado um estudo descritivo, com abordagem quantitativa, com 360 mulheres de 25 a 64 anos em duas Unidades Básicas de Saúde no município de São Mateus, ES. A média de idade das entrevistadas foi de 39,8 anos, onde $89,4 \%$ responderam conhecer ou já ter ouvido falar do HPV e a fonte de informação mais citada foi a TV/rádio com 53,1\%. Houve diferença estatisticamente significativa no conhecimento do vírus em relação à escolaridade, das 38 mulheres que não conhecem o HPV, 63,2\% tinham até oito anos de escolaridade. Das que conhecem o HPV, 81,1\% relataram que a via de transmissão é sexual, $18,0 \%$ desconheciam a existência de cura, $24,5 \%$ relataram não conhecer o que o vírus causa e 54,3\% nunca usam preservativos nas relações sexuais. Os dados permitiram concluir que o conhecimento sobre o HPV é limitado, evidenciando a necessidade de ações educativas voltadas para prevenção da infecção e seu agravamento.
\end{abstract}

RESUMO

PALAVRAS-CHAVE: Educação em saúde, Prevenção, Saúde da mulher.

\section{KNOWLEDGE OF WOMEN THAT USES SUS ABOUT THE HPV IN THE NORTHERN REGION OF THE ESPIRITO SANTO}

\begin{abstract}
The HPV is a virus that presents tropism by epithelial cells causing infections of the skin and mucous membranes, between $75 \%$ e $80 \%$ of world population acquire one or more types of HPV in some moment of their lives. The form of

ENCICLOPEDIA BIOSFERA, Centro Científico Conhecer - Goiânia, v.11 n.22; p.3239


transmission is mainly by sexual contact, this virus can originate precursor lesions of cervical cancer. Among the modes of prevention is the use of preservatives and the vaccination. This study evaluated the knowledge of women that uses SUS about the HPV. It was performed a descriptive study, with quantitative approach, with 360 women between 25 and 64 years old in two Basic Health Unit in the city of São Mateus, ES, Brazil. The average age of the interviewed was 39.8 years old, in which $89.4 \%$ answered known or already heard about the HPV, the most cited information source was TV/radio with $53.1 \%$. There was a statistically significant difference on the knowledge about the virus in relation to education, of 38 women that doesn't know HPV, $63.2 \%$ had up to 8 years of education. Of those that knows HPV, $81.1 \%$ knew about the sexual transmission, $18.0 \%$ didn't know about a existence of a cure, $24.5 \%$ didn't know the causes and $54.3 \%$ never uses preservative in their sexual relations. The data allowed to conclude that the knowledge about the HPV is limited, indicating the need of educational acts focused on HPV transmission and its aggravation.

KEYWORDS: Health education, Prevention, Women's Health

\section{INTRODUÇÃO}

O papilomavírus humano (HPV) é um vírus não envelopado com simetria icosaédrica, apresenta genoma de 8.000 pares de base (8kb) aproximadamente, DNA dupla fita e circular, formado por um capsídeo que possui 72 capsômeros. São pequenos vírus (50-55nm) pertencentes à família Papoviridae - gênero Papillomavirus, apresentam tropismo por células epiteliais, causando infecções na pele e mucosas (MURRAY et al., 2009).

Segundo a Organização Mundial da Saúde (OMS), as doenças sexualmente transmissíveis (DSTs) estão entre as dez principais causas de procura por serviços de saúde no mundo. A infecção por HPV é a DST mais comum, entre $75 \%$ a $80 \%$ da população adquirem um ou mais tipos de HPV em algum momento da vida, e estima-se que existem em torno de 600 milhões de pessoas infectadas mundialmente (INSTITUTO DO HPV, 2013).

A forma de transmissão do HPV é principalmente sexual, e ocorre pelo contato direto com a pele ou mucosa infectada e também pode acontecer transmissão durante o parto (INCA, 2015). Quando presentes, as lesões provocadas pelo vírus são contagiosas, podem ser assintomáticas e transitórias, porém algumas mulheres apresentam infecções persistentes que podem originar lesões pioneiras do câncer do colo do útero (WHO, 2015). Dos casos de câncer do colo do útero, 70\% estão associados aos tipos de alto risco oncogênico 16 e 18 do HPV, já os tipos de HPV 6 e 11 são considerados não oncogênicos e estão mais relacionados aos condilomas genitais e papilomas laríngeos (INCA, 2015).

O diagnóstico da infecção por HPV é realizado através da pesquisa direta do vírus ou indiretamente através das alterações provocadas pela infecção nas células e no tecido. Dentre as técnicas utilizadas para o diagnóstico, recomenda-se o exame preventivo Papanicolaou, colposcopia e peniscopia, detecção molecular que incluem captura híbrida e reação em cadeia de polimerase (INSTITUTO DO HPV, 2013). O tratamento tem por objetivo reduzir ou eliminar as lesões causadas pela infecção. Os métodos podem ser químicos, cirúrgicos e medicamentos com a finalidade de melhorar o sistema imune do paciente (BRASIL, 2013).

Algumas medidas podem ser tomadas para se prevenir a infecção por HPV, 
evitar ter vários parceiros sexuais, realizar a higiene pessoal e utilizar preservativos durante as relações sexuais. Embora o uso de preservativo durante todo o contato sexual seja recomendado como prevenção, o mesmo não protege totalmente da infecção por HPV, pois não cobre todas as áreas passíveis de serem infectadas. Recentemente, foram desenvolvidas e registradas duas vacinas contra HPV, a quadrivalente recombinante, que confere proteção contra HPV tipos 6, 11, 16 e 18, e a vacina bivalente que confere proteção contra HPV tipos 16 e 18 (BRASIL, 2013).

Em 2014 a vacina quadrivalente contra HPV foi incluída no Calendário Nacional de Vacinação, disponibilizada na rede pública para as adolescentes entre 11 e 13 anos. A vacina também foi oferecida para as meninas entre 9 e 11 anos a partir de março do ano de 2015 (BRASIL, 2015). Frente ao exposto, acredita-se necessária a investigação do conhecimento das mulheres sobre o HPV, para que se possa colaborar com futuras ações de educação em saúde no sentido de esclarecer dúvidas e promover a conscientização, buscando contribuir para a melhor qualidade de vida das mulheres.

\section{MATERIAL E MÉTODOS}

Trata-se de um estudo descritivo, com abordagem quantitativa, que analisou o conhecimento de usuárias de duas Unidades Básicas de Saúde (UBS) do município de São Mateus (ES), sobre o HPV.

O estudo incluiu mulheres residentes no município de São Mateus, usuárias do SUS na faixa etária de 25 a 64 anos, preconizado pelo Ministério da Saúde para coleta do exame preventivo Papanicolaou. O cálculo para amostra aleatória simples foi realizado com base no número estimado de mulheres maiores de 18 anos (38.097) residentes no município segundo Censo Demográfico 2010 (IBGE, 2010), considerando nível de confiança de $95 \%$, erro amostral de 5\%.

Os dados foram coletados de mulheres que concordaram em fazer parte da pesquisa e se dispuseram a responder a entrevista por meio de um formulário estruturado aplicado por acadêmicas do curso de farmácia, entre os meses de setembro, outubro e novembro do ano de 2014. O formulário continha informações pessoais (idade, escolaridade, renda, estado civil e número de filhos) e sobre HPV (vias de conhecimento, forma de transmissão, causa, cura, prevenção e vacinação).

As mulheres foram convidadas a participarem do estudo enquanto aguardavam pelo atendimento médico ou de enfermagem na sala de espera da UBS. Os objetivos da pesquisa foram esclarecidos às mulheres selecionadas, que assinaram um Termo de Consentimento Livre e Esclarecido.

Os dados foram digitados em planilha eletrônica Excel e analisados por meio do programa estatístico BioEstat 5.0. Realizou-se análise descritiva com porcentagem e para associação foi aplicado o teste qui-quadrado, considerando significativo $p<0,05$.

A pesquisa foi submetida ao Comitê de Ética em Pesquisa com Seres Humanos do CEUNES-UFES, de acordo com a Resolução 466/2012 do Conselho Nacional de Saúde, sob o no CAAE: 34443214.5.0000.5063.

\section{RESULTADOS}

O grupo foi composto por 360 mulheres, com idade entre 25 e 64 anos, média de 39,8 anos. Entre as mulheres, $89,4 \%(n=322)$ responderam que conheciam ou já ouviram falar do HPV. Das 322 mulheres que afirmaram conhecer ou ter ouvido falar 
no HPV, $183(56,8 \%)$ possuem tempo de escolaridade superior a oito anos. No entanto, das 38 mulheres que não conhecem ou nunca ouviram falar sobre o vírus, $63,2 \%(n=24)$ tinham até oito anos de escolaridade, sendo estatisticamente significativa a diferença no conhecimento do vírus em relação a escolaridade (Figura 1). Ainda das que afirmaram conhecer o HPV, $82,3 \%$ tinham renda familiar de até dois salários mínimos, $74,0 \%$ relataram ter de um a três filhos e $76,70 \%$ tinham companheiro (Tabela 1).

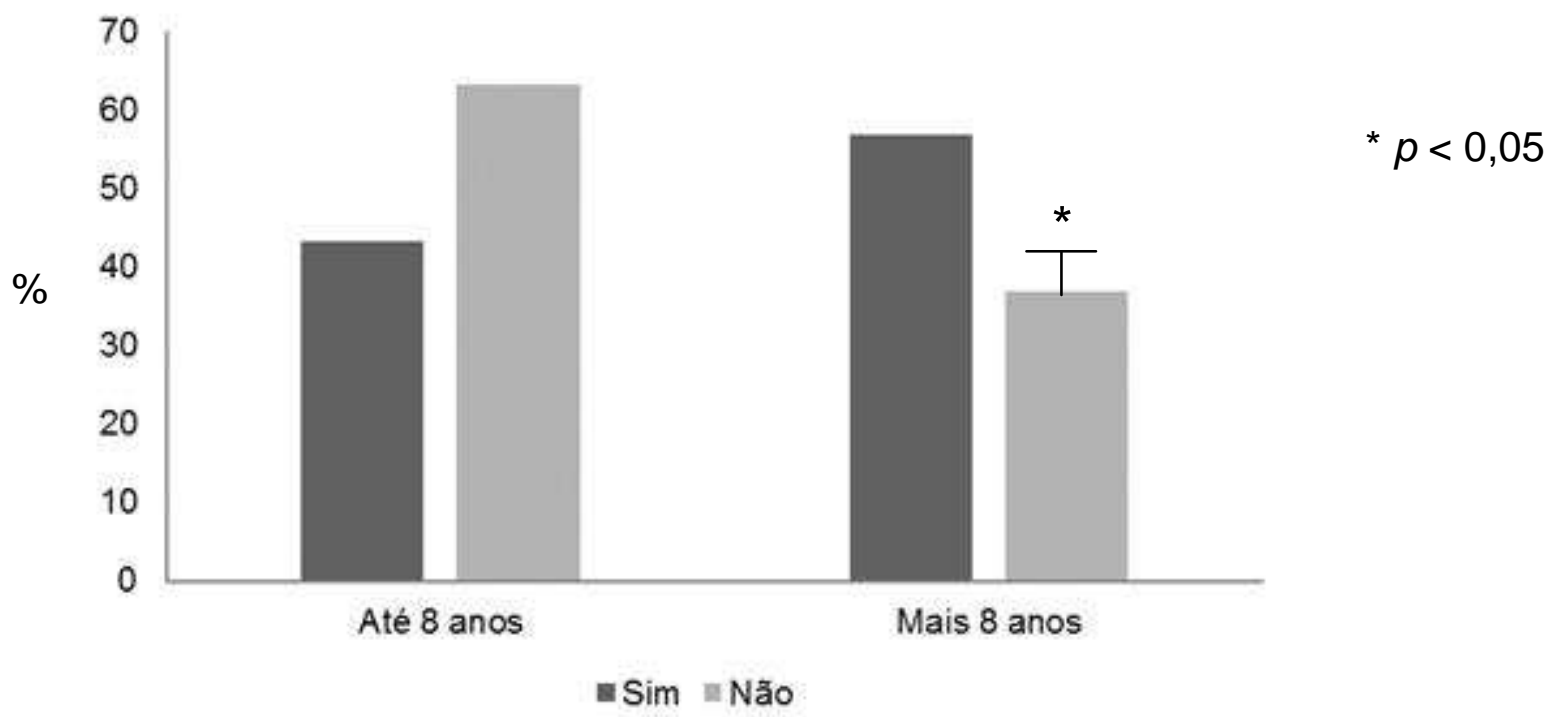

FIGURA 1 - Relação entre a frequência (\%) de mulheres que conhecem ou não o HPV com o tempo de escolaridade em anos. São Mateus, 2014

TABELA 1 - Conhecimento sobre o HPV por usuárias do SUS, segundo características socioeconômicas. São Mateus, 2014.

\begin{tabular}{|c|c|c|c|c|c|c|}
\hline \multirow{3}{*}{ Variável } & & \multicolumn{4}{|c|}{ Conhece ou já ouviu falar do HPV } & \multirow[b]{3}{*}{$p$} \\
\hline & & \multicolumn{2}{|c|}{ SIM } & \multicolumn{2}{|c|}{ NÂO } & \\
\hline & & $\mathrm{n}$ & $\%$ & $\mathrm{n}$ & $\%$ & \\
\hline Escolaridade (anos) & 0 a 8 & 139 & 43,2 & 24 & 63,2 & 0,0301 \\
\hline & Acima de 8 & 183 & 56,8 & 14 & 36,8 & \\
\hline & Até 2 salários & 265 & 82,3 & 33 & 86,8 & \\
\hline Renda familiar & $\begin{array}{c}3 \text { salários mínimos ou mais } \\
\text { Sem companheiro }\end{array}$ & $\begin{array}{l}57 \\
75\end{array}$ & $\begin{array}{l}17,7 \\
23,3\end{array}$ & $\begin{array}{c}5 \\
11\end{array}$ & $\begin{array}{l}13,2 \\
28,9\end{array}$ & 0,6352 \\
\hline Estado marital & $\begin{array}{c}\text { Com companheiro } \\
\text { Não tem } \\
1 \text { a } 3\end{array}$ & $\begin{array}{c}247 \\
27 \\
238\end{array}$ & $\begin{array}{c}76,7 \\
8,3 \\
74,0\end{array}$ & $\begin{array}{c}27 \\
2 \\
26\end{array}$ & $\begin{array}{c}71,1 \\
5,3 \\
68,4\end{array}$ & 0,5672 \\
\hline Número de filhos & 4 ou mais & 57 & 17,7 & 10 & 26,3 & 0,3856 \\
\hline
\end{tabular}


Entre as mulheres que já conhecem ou ouviram falar sobre o HPV, quando questionadas sobre as principais fontes de informação, as mais citadas foram televisão/rádio com 53,1\% ( $n=171)$, agente comunitário com 33,9\% ( $n=109)$ e médico com 33,2\% ( $n=107)$ (Figura 2).

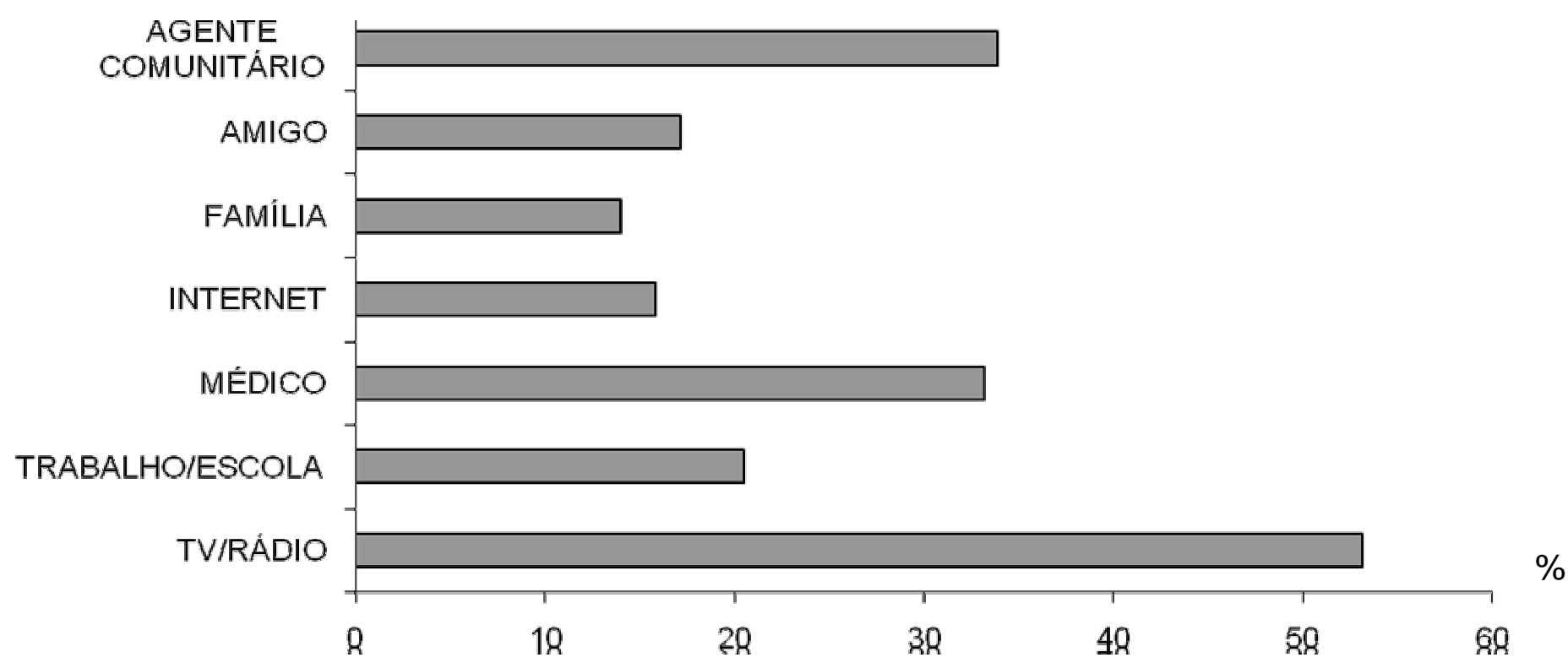

FIGURA 2 - Frequência das vias de comunicação citadas pelas usuárias do SUS que conhecem ou já ouviram falar sobre o HPV. São Mateus, 2014.

Quanto à forma de transmissão do vírus, das 322 entrevistadas que conhecem ou já ouviram falar do HPV, 81,1\% $(n=261)$ afirmaram ser pela relação sexual, $8,7 \%(n=28)$ por meio de objetos íntimos e 13,7\% ( $n=44)$ não sabiam como ocorria o contágio.

Em relação ao que o HPV causa, $60,9 \%(n=196)$ das 322 usuárias do SUS que já ouviram falar do vírus mencionaram ser o Câncer do Colo do Útero, 15,5\% $(n=50)$ acreditam que cause verrugas na genitália (Figura 3). No entanto, $24,5 \%$ $(n=79)$ das mulheres que relataram conhecer ou ter ouvido falar do HPV não sabem o que o vírus causa.

A porcentagem das respostas sobre fontes de informação, formas de transmissão e sobre o que o HPV causa foi calculada levando-se em consideração cada alternativa marcada, já que nessas perguntas as participantes poderiam responder com mais de uma opção. 


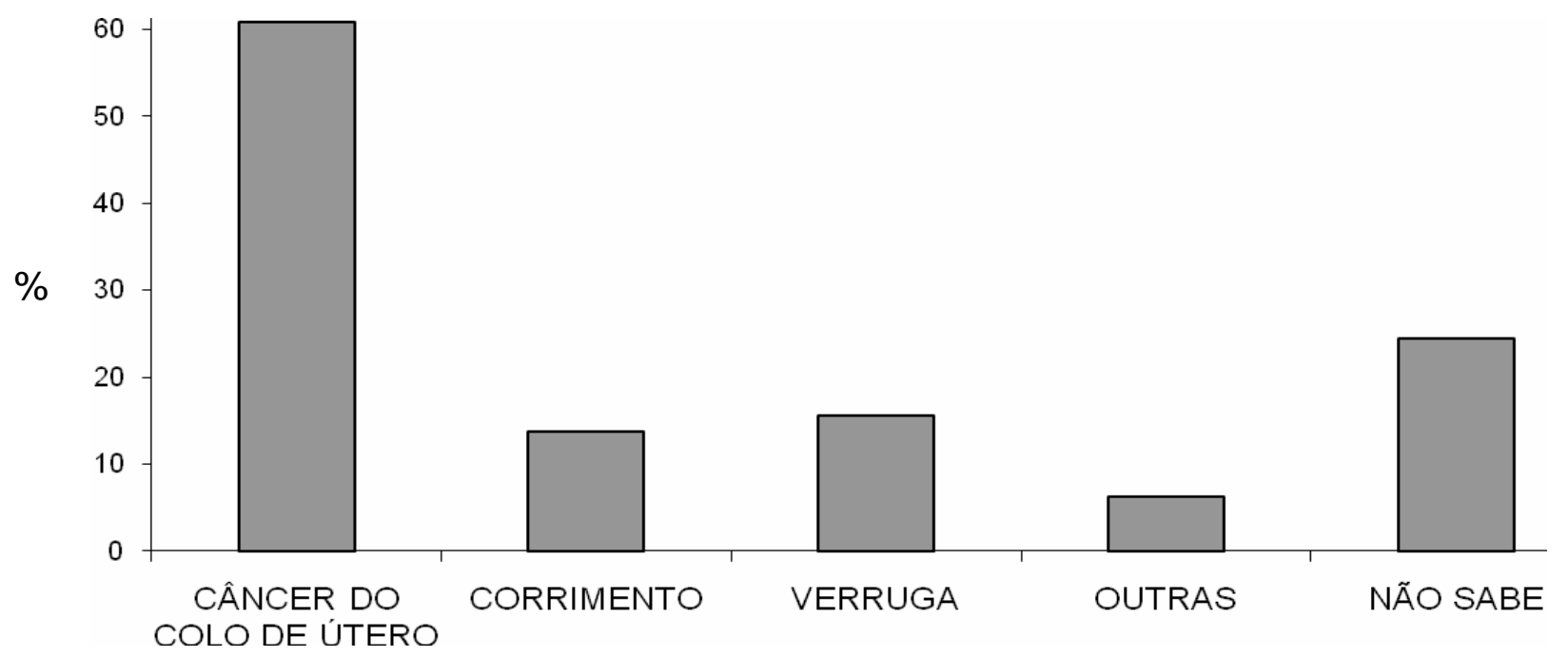

FIGURA 3 - Manifestações clínicas causadas pelo HPV de acordo com as respostas das usuárias do SUS expressas em porcentagem. São Mateus, 2014.

Quando indagadas sobre a cura do HPV, 64,2\% (207/322) das mulheres disseram que há cura, em contrapartida 18,0\% (58/322) não souberam responder. No que diz respeito à prevenção da doença, $87,8 \%$ (283/322) responderam que existe e $75,8 \%$ (244/322) já ouviram falar sobre a vacina contra HPV.

Dentre todas as usuárias do SUS participantes do presente estudo, 50,6\% $(\mathrm{n}=182)$ nunca participaram de nenhuma atividade educativa sobre doenças sexualmente transmissíveis (DSTs), HPV ou Câncer do Colo do Útero e entre as que já participaram, 70,3\% disseram ter sido na Unidade Básica de Saúde.

Em relação à atividade sexual das participantes, 44,4\% ( $n=160)$ iniciaram a vida sexual entre 15 a 18 anos, $43,8 \%(n=158)$ com mais de 18 anos e $11,4 \%(n=41)$ com menos de 14 anos. Nas relações sexuais, 54,3\% ( $n=195)$ nunca utilizam preservativo, 28,6\% ( $n=103)$ utilizam às vezes e apenas $16,9 \% \quad(n=61)$ sempre utilizam, apenas uma participante não era sexualmente ativa. Ainda, 94,4\% $(n=340)$ disseram nunca ter tido HPV, verrugas nas genitais ou Câncer de colo do Útero.

\section{DISCUSSÃO}

No presente estudo, observou-se que $89,4 \%$ das participantes conhecem ou já ouviram falar do HPV, entre essas usuárias $81,1 \%$ responderam que a forma de transmissão é a sexual. Entretanto, 13,7\% não sabiam como ocorria o contágio, $24,5 \%$ não sabiam o que o HPV causa e 18,0\% não sabiam responder se existe cura. Em estudo realizado com mulheres com idade entre 40 e 60 anos, $86,7 \%$ das entrevistadas possuíam conhecimento da sigla HPV (SILVEIRA et al., 2011). Em outro estudo realizado no município de Ribeirão Preto - SP, 81,5\% das mulheres afirmaram saber que o HPV é transmitido sexualmente (PIMENTA et al., 2014).

A infecção pelo HPV, que é o principal fator de risco para o desenvolvimento das lesões precursoras do câncer do colo do útero, pode levar ao aumento do número de casos deste tipo de câncer, devido à falta de conhecimento sobre este vírus (ARRUDA et al., 2013). Segundo estimativas do Instituto Nacional do Câncer (INCA), em 2014 eram esperados 15.590 novos casos em todo o Brasil e a 
estimativa para a região Sudeste seria 10,15 casos por 100 mil mulheres (INCA, 2014).

No estudo de OSIS et al., (2014), dos entrevistados que ouviram falar sobre o HPV, 70,6\% têm mais de oito anos de estudo, enquanto entre os que não ouviram falar sobre o vírus, 55,7\% possuem até oito anos de estudo, mostrando ser estatisticamente significativa a relação entre 0 nível de escolaridade $e \quad 0$ conhecimento sobre o HPV. Este estudo também mostra diferença estatisticamente significativa nesse parâmetro, entre as mulheres que relataram conhecer ou ter ouvido falar do HPV, 56,8\% possuem tempo de escolaridade maior de oito anos e entre as que nunca ouviram falar, a maioria (63,2\%) possui tempo de escolaridade de até oito anos. A educação aumenta o nível de importância com os cuidados da saúde e proporciona ao indivíduo melhor compreensão das informações a respeito da doença, desta forma os resultados demonstram a necessidade de ações educativas com a população, para ampliar o conhecimento da mesma. A informação deve ser transmitida levando em conta o nível de escolaridade e capacidade de entendimento, para facilitar a assimilação do conteúdo (OSIS et al., 2014).

Quando perguntado sobre ações educativas, 50,6\% das entrevistadas não participaram de nenhuma atividade educativa sobre DSTs, HPV ou câncer do colo do útero. Este é um resultado importante já que as atividades de educação em saúde podem contribuir para a prevenção de doenças, maior adesão da população aos tratamentos disponíveis, além de modificar a forma de pensar e agir sobre determinadas patologias (MANZO et al., 2011). No presente estudo, das 49,5\% $(n=178)$ de usuárias do SUS que participaram de alguma atividade, $70,3 \%$ responderam que o local de realização foi a Unidade Básica de Saúde. Assim, os profissionais de saúde desempenham papel fundamental na prática e elaboração de ações educativas, pois levam ao conhecimento da população as informações corretas sobre as doenças (MANZO et al., 2011).

Com relação à fonte de informação, observou-se que a televisão/rádio foi a mais citada para a obtenção de conhecimento de HPV, tendo sido relatado por $53,1 \%$ das entrevistadas que já ouviram falar sobre o vírus. Em vista disto, o conhecimento proveniente de médicos $(33,2 \%)$ e agentes comunitário $(33,9 \%)$, foi inferior a informação procedente da mídia. Embora o acesso à mídia seja amplo pela população, as informações repassadas podem não ser totalmente suficientes, adequadas e entendidas. Em contrapartida, o agente comunitário e o médico, que são figuras educadoras em saúde, são capazes de transmitir informações adequadas e esclarecer dúvidas (SORENSEN et al., 2012).

No presente estudo $87,8 \%$ das entrevistadas afirmaram que existe forma de prevenção do HPV, porém 54,3\% disseram nunca usar preservativos durante as relações sexuais. De acordo com a pesquisa realizada com adolescentes de uma escola na região sul do município de São Paulo 59,7\% relataram não ter utilizado preservativo na última relação sexual (CIRINO et al., 2010). Uma hipótese para a não utilização de preservativos seria a confiança no parceiro sexual. Apesar do preservativo não prevenir totalmente a infecção pelo HPV, é um método indicado. $O$ preservativo feminino que cobre também a vulva, evita mais eficazmente o contágio se utilizado desde o início da relação sexual, sendo essa uma vantagem sobre o preservativo masculino já que este método também não consegue cobrir todas as áreas passíveis de lesões (BRASIL, 2013).

Quanto à vacinação, no estudo realizado em Campinas no ano de 2011, menos de 9\% dos entrevistados conheciam a vacina contra HPV (OSIS et al., 2014). 
No presente estudo, realizado no ano de $2014,75,8 \%$ das mulheres afirmaram ter este conhecimento. Esta variação pode ser justificada porque no ano de 2011 estavam disponíveis as vacinas apenas na rede privada de saúde e no ano de 2014, a vacinação contra o HPV foi disponibilizada na rede pública de saúde para meninas de 11 a 13 anos.

Em estudo realizado em Ribeirão Preto - SP, mais da metade das entrevistadas $(53,2 \%)$ relataram ter dado início a atividade sexual antes dos 16 anos de idade (PIMENTA et al., 2014). Das entrevistadas do presente estudo, 11,4\% deram início à atividade sexual com menos de 14 anos, $44,4 \%$ dos 15 aos 18 anos. O início precoce da atividade sexual evidenciado nos dados anteriores, é considerado um fator de risco para a infecção pelo HPV (FEDRIZZI et al., 2008; PIMENTA et al., 2014). Provavelmente pela maior exposição da zona de transformação da cérvice, o que favorece a infecção pelo vírus, que poderá alcançar as células basais, facilitando a replicação e desenvolvimento de lesões precursoras de neoplasias ou neoplásicas. Além disso, na adolescência ocorre a menor produção de muco cervical, que serviria como barreira protetora contra o HPV (FILHO et al., 2003, COSER et al., 2012).

\section{CONCLUSÃO}

Os resultados levam a concluir que uma parte das usuárias do SUS entrevistadas, ainda que já tivessem ouvido falar sobre HPV, possuem conhecimentos limitados em relação ao que o vírus causa, se existe cura e formas de transmissão.

Nesse sentido, atividades educativas voltadas para o esclarecimento dos fatores de risco ligados ao comportamento sexual e ampliação das informações a respeito do vírus poderiam ser estratégias eficientes para o controle da transmissão do HPV, consequentemente esta medida resultaria em um impacto positivo a saúde da população, já que este vírus funciona como porta de entrada do câncer do colo do útero.

\section{REFERÊNCIAS}

ARRUDA, F. S.; OLIVEIRA F.; M, LIMA R. E.; PERES A. L. Conhecimento e prática na realização do exame Papanicolaou e infecção por HPV em adolescentes de escola pública. Rev. Paraense de Medicina, v. 27, n.4, p. 59-66, 2013.

BRASIL. Ministério da Saúde. Secretaria De Vigilância Em Saúde. Guia Prático Sobre o HPV Perguntas e Respostas. Brasília: Ministério da Saúde, 2013. [acesso em 12 jun. 2015]. Disponível em: <http://www.suvisa.ba.gov.br/sites/default/files/Guia\%20Pr\%C3\%A1tico\%20HPV\%20 Perguntas\%20e\%20Respostas_0.pdf>.

BRASIL. Ministério da Saúde. Vacinação contra o HPV. [acesso em 12 jun. 2015]. Disponível em: <http://portalarquivos.saude.gov.br/campanhas/hpv>.

CIRINO, F. M. S. B.; NICHIATA, L. Y. I.; BORGES, A. L. V. Conhecimento, atitude e práticas na prevenção do câncer do colo uterino e HPV em adolescentes. Escola Ana Nery Rev. de Enfermagem. v. 14, n.1, p.126-34, 2010.

COSER, J.; FONTOURA, S.; BELMONTE, C.; VARGAS, V. R. A. Relação entre 
fatores de risco e lesão precursora do câncer do colo do útero em mulheres com e sem ectopia cervical. RBAC. v. 44, n.1, p.50-4, 2012.

FEDRIZZI, E. N.; SCHLUP, C. G.; MENEZES, M. E.; OCAMPOS, M. Infecção pelo papilomavírus humano (HPV) em mulheres de Florianópolis, Santa Catarina. DST J bras Doenças Sex Transm. v. 20, n.2, p.73-79, 2008.

FILHO, A. L.; ETLINGER, D.; GOMES, N. S.; CRUZ, S. V.; CAVALIERI, M. J. Frequência de esfregaços cérvico-vaginais anormais em adolescentes e adultas: revisão de 308.630 casos. Rev. Inst. Adolfo Lutz. v. 62, n.1, p.31-34, 2003.

IBGE - INSTITUTO BRASILEIRO DE GEOGRAFIA E ESTATístiCA. Censo Demográfico 2010. [acesso em 20 mar. 2015]. Disponível em:<http://www.cidades.ibge.gov.br/xtras/perfil.php?lang=\&codmun=320490\&search =espirito-santo|sao-mateus|infograficos:-informacoes-completas $>$.

INSTITUTO DO HPV. Guia do HPV: Entenda de vez os papilomavírus humanos, as doenças que causam e o que já foi possível fazer para evita-los. São Paulo, 2013. [acesso em 02 jun. 2015]. Disponível em: <http://www.incthpv.org.br/Artigos/Default.aspx?pag=cartilhas >.

INCA - INSTITUTO NACIONAL DE CÂNCER JOSÉ ALENCAR GOMES DA SILVA. Estimativa 2014: Incidência de Câncer no Brasil. [acesso em 12 jun. 2015]. Disponivel em: <http://www.inca.gov.br/estimativa/2014/sintese-de-resultadoscomentarios.asp>.

INCA - INSTITUTO NACIONAL DE CÂNCER JOSÉ ALENCAR GOMES DA SILVA. HPV e câncer - Perguntas mais frequentes. Rio de Janeiro, 2015. [acesso em 02 jun. 2015]. Disponível em: <http://www1.inca.gov.br/conteudo_view.asp?id=2687>.

MANZO, B. F.; SILVA J. M. A.; SOUZA, R. C.; SOUZA, R. S.; PEREIRA, S. M. Fatores relacionados a não continuidade da realização do exame citológico Papanicolau. Rev. Percurso Acadêmico. v. 1, n.2, p.227-241, 2011.

MURRAY, P.R.; ROSENTHAL, K.S.; PFALLER, M.A. Microbiologia Médica. 6. ed. Rio de Janeiro: Elsevier. p.486-494, 2009.

OSIS, M. J. D.; DUARTE, G. A.; SOUSA, M. H. Conhecimento e atitude de usuários do SUS sobre o HPV e as vacinas disponíveis no Brasil. Rev. Saúde Pública. v. 48, n.1, p.123-133, 2014.

PIMENTA, A. T. M.; MELLI, P. P. S.; DUARTE, G.; QUINTANA, S. M. Conhecimento de mulheres sobre alguns aspectos do papilomavírus humano. Medicina (Ribeirão Preto). v. 47, n.2, p.143-8, 2014.

SILVEIRA, C. F.; MELO, M. M.; RODRIGUES, L. R.; PARREIRA, B. D. M. Conhecimento de mulheres de 40 a 60 anos sobre o papilomavírus humano. Rev. Rene. 2011;v. 12, n.2, p.309-15, 2011. 
SORENSEN, K.; VAN DEN BROUCKE, S.; FULLAM, J.; DOYLE, G.; PELIKAN, J.; SLONSKA, Z.; BRAND, H. Health literacy and public health: A systematic review and integration of definitions and models. BMC Public Health. v. 80, n.12, 2012.

WHO - WORLD HEALTH ORGANIZATION. Human papillomavirus (HPV) and cervical câncer. 2015. [acesso em 14 jun. 2015]. Disponível em: <http://www.who.int/mediacentre/factsheets/fs380/en>. 